\title{
Employer Branding as a Contemporary Challenge In the 2020 Workplace; During the Era of Transformational Change
}

\author{
Dr. Bassant Adel Mostafa
}

Lecturer, British University in Egypt

\begin{abstract}
Nowadays in the dynamic transformational environment, organizations face many challenges to become more knowledge-based, more emphasis on innovation and technology, as well as facing intensive competition for attracting and retaining a high-quality workforce. Those organizations seek employees from different cultural backgrounds and more attention is given to the "Generation Z" namely digital talents; entering the 2020 market place. So organizations should meet the previously mentioned challenges' by differentiating themselves from other competitors in the labor market and enhancing their employer attractiveness as a tool to ensure competitive advantage for the organizations.

This research aims at getting a clearer understanding of Generation Z perception of 2020 workplace and reflecting on how an employer branding (EB) strategy can be the answer for differentiation, through the delivery of a value proposition based on functional, symbolic and economical benefits, which should be consistent with the needs of this new generation. To carry out this mission, employers need to have a strong and unique value proposition and, at the same time, need to know how to communicate this value to potential candidates (Generation Z) using digital codes and channels. Generation Z is represented in this research by undergraduate students who are in their final year of study, selected from British University in Egypt.

The practical implication of this research should suggest the appropriate employer branding strategies and identify the relevant set of responsibilities required for organizations taking strategic steps toward "the war for talent."
\end{abstract}

Keywords: Employer Branding, Competitive Advantage, Resource-Based View, Digitalization, Generation Z.

\section{Introduction}

Many organizations around the world focus increasingly on the concept of the "Best Employer Status" or the "Best Place to Work", for the aim of differentiating themselves from competitors, this process of differentiation is becoming even more important today, as organizations are operating (Mičík and Mičudová, 2018), in an era where employees' skills and knowledge are among the main competitive enablers (Botha et al., 2011).

In addition, the rise of global development, technological advancements, greater dependence on data analytics (Sharma et al., 2019), talent shortage (Botha et al., 2011) and changes in workforce demographics (App et al., 2012), in particularly; Generation Z entering the market place with different needs and expectations, causing difficulties for employers in attracting the best employees for achieving a competitive advantages. These

* This article was submitted in February 2020, and accepted for publishing in March 2020.

(c) Arab Administrative Development Organization- League of Arab States, 2021, pp 409-420، DOI: 10.21608/aja.2021.176918 
evolving conditions are forcing employers to rethink their approach on how to retain and attract a highly qualified caliber from a diverse workforce using digital tools and techniques (Sharma et al., 2019).

But one thing that remains true is that people are a company's most valuable asset. Any employer that can develop, retain, and attract great people will have the intellectual capital to compete far into the future, and this is the essence of contemporary employer branding (Bakanauskienė et al., 2014). Employer branding is developing as a best practice to ensure that companies are prepared for an unpredictable future (Jiang \& lles, 2011). Human capital is vital for a company's survival and development since human capital is its most valuable resource (Xie et al., 2015) which ensures its competitive sustainability (Botha et al., 2011).

Human Resource practitioners are moving towards placing a high premium on employer brand as a critical success factor for companies striving for competitive advantage in the war for talents (Crous, 2008). Moreover, to address this issue, employers need to understand what attracts new talents to organizations today; Hieronimus et al. (2005) emphasize the need for employers to determine which attributes are the most important to specific types of potential employees.

Potential candidates, in this case, are the "Generation Z" who will make up a large share of the global workforce by the year 2020, "Generation Z" (some of them are now fresh graduates, while others are about to be graduated and enter the market place) is a specific social group who has several characteristics and expectations different from the previous generations, which means that employers cannot use the same strategies that have been in use so far (Mičík, and Mičudová, 2018). Therefore, it is essential to recognize the role played by employer branding in this process of attracting and sustaining a continuous flow of talents through competitive employment offer that fits "Generation Z" needs and preferences.

This research is structured in several sections. First, it starts by explaining the research significance and then, the objectives of the research are presented, second, a review of the literature on employer branding as a source of competitive advantage and the main characteristics of Generation $\mathrm{Z}$ in the workplace are illustrated. In the following section, the exploratory interview results are presented. After presenting the results, a proposed roadmap for employer branding strategy in practice is elaborated. To end up by a conclusion, highlighting the research main implication and proposing a future line of research.

\section{Research Significance}

Digital innovations and demographic dividend specifically the emergence of Next Generation Employees "Generation $Z$ " are redefining the organizational human capital management practices and employer branding strategy, the sustainability of any organization depends on the talent pool of the employer (Mukherjee et al., 2018). Up to the researcher's knowledge, very few studies have tackled "Generation Z" perception of the 2020 marketplace in Egypt.

The increasing presence of Generation Z (means those who were born between the years 1995 through 2010) presents new challenges for employers and is causing many businesses to re-think their working practices, one key factor that differentiates "Generation $Z$ " is that they have grown up in the age of information technology and social media that shaped the way they view the world, including their expectations of the workplace. Moreover, failure to effectively attract and engage these new workers will significantly affects organizations' competitiveness in the long run (Mukherjee et al., 2018). 
This research aims at reflecting on how an employer branding (EB) strategy can be the answer for differentiating one employer over the other, through the delivery of a unique value proposition consistent with the diverse needs and expectations of potential employees more specifically "Generation Z" who constitutes almost $40 \%$ of the Egyptian population (Worldometer, 2020). The outcomes of this study can be used by employers to increase their attractiveness among talented young people looking for jobs.

\section{Research Objectives}

- To identify how organizations position themselves as an attractive employers in the labor market.

- To find out to what extent employers can attract generation $Z$ with different needs and expectations than previous generations.

- To identify the most attractive employment attributes for the generation in question.

\section{Literature Review}

\section{Employer Branding as A Source of Competitive Advantage}

In Strategic Human resource management literature, attention is given to the resource-based view of the organizations as a way to describe how human resources, can be a source of sustainable competitive advantage for the organization (Wright and McMahan, 1992). Organizations gain sustainable competitive advantage by implementing value-enhancing strategies that differentiate them from their competitors and are difficult for competitors to immitate (Barney, 1991).

The resource-based view proved that an organizations' competitive advantage and its success depend on the supply and effective use of resources. If resources are valuable, rare, non-substitutable, and inimitable, they are considered as important and strategic and enable the organization to gain a competitive advantage (Barney, 1991). Thus Wright and McMahan (1992) said that human resources have the potential to be a strategic source for achieving a sustainable competitive advantage, though they also note that to do so, the employees must be both highly skilled and motivated that is, a high-quality workforce.

Building on the above theory, for organizations to position themselves as an attractive employers, they should be able to attract talents, therefore, the concept of employer branding has been established (Ambler and Barrow, 1996; Backhaus and Tikoo, 2004; Lievens et al. 2007). Employer branding is focused on building the brand name of the employer as a great place to work in the job market, it is focused on developing a positive relationship with existing as well as prospective employees, a strong employer brand should be aligned with the organization's vision, values, strategy and culture, becoming a critical factor in creating employee engagement (Mukherjee et al., 2018).

Ambler and Barrow (1996: 187) define EB as: "the package of functional, economic, and psychological benefits provided by employment, and identified with the employing company." Thus an employer brand contains multiple facets, all of which should express what the organization, as an employer, represents. Through these facets, the organization aims to achieve status as an employer of choice (Backhaus and Tikoo, 2004).

Employer branding is defined as the "summation of an organization's efforts to communicate to both current employees and prospective candidates that the organization is a great place to work in" 
(Al Badawy et al., 2017: 4). This could be aided by the functional, psychological and economic benefits provided when working under the name of the organization (Ambler and Barrow, 1996; Moroko and Uncles, 2008). Al-Badawy et al. (2017) stated that employer branding represents an organization's effort to communicate to internal and external audiences what makes it both desirable and different as an employer.

Employer branding also aims at internal retention of high performing employees and external attraction of unique candidates, all of whom help the organization gain a competitive advantage (Suikkanen, 2010). By establishing an employer brand, organizations aim to provide a unique employment offering that positively differentiates them from competitors. If they can create an image as a great place to work, they likely can attract and retain a skilled and motivated workforce (Ambler and Barrow, 1996; Moroko and Uncles, 2008).

Employer branding is becoming important for four reasons. First, it contributes directly to the competitive advantage of the company as human resources acquired have become rare, valuable and non-substitutable along with being difficult to imitate (Suikkanen, 2010). Second, applying the concept provides for a solid corporate identity which attracts the best of talent allowing individuals to have great experience in the company (Elving et al., 2013).

Third, employer branding signals out the candidates who will not fit within the organization, hence, ensuring that only the right applicants who might achieve high productivity and tenure remaining. Fourth, employer branding achieves efficiency and effectiveness as recruitment decisions are made correctly and the rate of turnover is reduced (Al Badawy et al., 2017). Organizations can no longer bear the costs, in terms of recruitment, compensation, and retention, associated with losing employees, so building a brand for employees can also increase organizational success because it has the potential to minimize costs through more efficient and effective communication (App et al., 2012).

\section{Creating a Differentiated Employer Value Proposition (EVP)}

Backhaus and Tikoo (2004) argued on how organizations could develop and implement employer branding, and in particular how to develop the underlying employer value propositions. That conveys a message to current and prospective employees about the uniqueness of the organizational work experience ( Mičík and Mičudová, 2018).

This latter issue, how to create a winning value proposition, answering the question "Why would a talented person choose to work here?" (Lundkvist, 2017: 9), should be clearly defined and be seen as crucial to the process of developing an employer brand, similar to a unique selling proposition in the consumer market, the set of provided benefits should ensure a good employee value proposition (Ambler and Barrow, 1996; Backhaus and Tikoo, 2004; Lundkvist, 2017).

According to EB definition, the EVP should contain functional, economical, and psychological benefits (Ambler and Barrow, 1996; Lievens and Highhouse, 2003; Lievens et al., 2007). On the one hand, potential and existing employees seek instrumental (i.e., functional/economic) benefits, so they evaluate objective and factual employment attributes (e.g., salary). On the other hand, they need symbolic (i.e., subjective/ psychological) benefits, which refer to the intangible attributes that people assign to an employer (e.g., job satisfaction, reputation) (Lievens and Highhouse, 2003). 
Lievens et al. (2007) discuss the relationship of applicant attraction, instrumental benefits, and symbolic benefits. They argue that instrumental employment attributes are increasingly similar and can be easily replicated by other competitors, so organizations additionally must provide symbolic employment attributes to differentiate themselves from competitors in the labor market, the possibility of comparing different employment offers reinforces the need for organizations to create greater appeal as an employer (Lievens and Highhouse, 2003).

A differentiated EVP provides a clear explaination of what sets a company apart as an employer and is defined as "the unique set of attributes and benefits that will motivate target candidates to join a company and current employees to stay" (Botha et al., 2011:3 ). EVP is informed by five main elements, namely: work environment and affiliation (this includes values, culture, quality of colleagues, managers, and leaders), work content including challenging work and work-life balance, benefits including development and career growth (indirect financial reward), and remuneration (direct financial reward), (Munsamy and Bosch Venter, 2009; Botha et al., 2011). According to Munsamy and Bosch Venter (2009), organizations are at risk of turnover when their EVP is perceived as less competitive than that of other organizations.

Thus, there are no standards or templates for what attributes an EVP should compile and if "blueprints" existed for good attributes, any strategy to imitate others would not provide a competitive edge to create unique offerings in comparison with competitors (Moroko and Uncles, 2008). The mission is to find authentic, unique, and attractive attributes is a challenge and cannot be brought into reality without clear proactive support from top leaders (Lundkvist, 2017).

\section{"Generation Z" on the labor market}

New generation entering the labor market "Generation $Z$ " who significantly differ from their predecessors (Kuczerska, 2018). The term "Generation Z" refers to those born from 1995 through 2010 (Macalik and Sulich 2019).

Generation $\mathrm{Z}$ is the first generation born into a digital world. They make up 40 percent of the Egyptian population (worldometer, 2020). This is greater than any previous generation, and it won't be long before this generation is dominating the workforce, recent research by Manpower Group suggests they will make up approximately 24 percent of the global workforce by the year 2020 (Tabaka, 2019).

The vast majority of researchers note that the internet entirely shapes the "Generation Z" world; they do not know life without social media, smartphones, and computers (Macalik and Sulich 2019). Although millennials have been labeled as digital natives, Mihalcea (2017) indicates that in reality, Generation Z has proficiency in digital technologies.

Numerous studies confirm that "Generation Z" is "we-generation" who are more socially oriented, strongly interested in social problems (Macalik and Sulich 2019), corporate social responsibility and that they engage in worldwide ecological issues like global warming and climate change, alternative energy sources,

pollution, recycling trends, etc. (Patel, 2017 and Masdar, 2019). A “Masdar Gen Z Global Sustainability Survey " is conducted in 2016 on a sample of respondents from Generation Z from 20 Countries, revealed that the vast majority of respondents especially in emerging economies, have high demands on the private sector and want to lean towards careers in sustainability (Masdar, 2019). 
The following part summarizes "what employers should keep in mind when hiring Generation Z employees" according to Tabaka (2019):

They are born into a world of struggle, they are more risk-averse; Gen Z-ers are expected to stay on the job longer, in search for stability, but it also means that employers will need to offer financial security through raises and rapid promotion for long-term stability. They are not bound by work schedules; Generation $Z$ employees will work anywhere, at any time. Flexible schedules remain vital for this generation but it is expected that youngest workers cease to be productive once they walk out the door.

Tabaka (2019) added that they use social media differently; Facebook is the preferred social media platform for every age group except Generation Z. This generation prefers YouTube, Snapchat, and Instagram. They have a high desire to make a difference; Generation $Z$ considers the opportunity to do this through their work, so they are strongly meaningful when choosing an employer.

Kislingbury (2019) added that "generation Z" wants a better work-life balance. According to Forbes, $38 \%$ of Generation $Z$ has made this their top priority when weighing up job offers. Satisfying this demand means they're more likely to stay at a company for 5 years or more. The remote working practice is one way to improve staff's work-life harmony; they want the chance to work from anywhere.

More feedback; they prefer frequent feedback so they can change their behavior accordingly, this extra employer effort can boost staff retention as more than two-thirds of Generation Z says increased supervisor feedback encourages them to stay in their job, in addition to improved corporate social responsibility policies are a key demand from them, and this is most prominent regarding equality and diversity, $77 \%$ of Generation Z chooses their employer based on the diversity of their staff, diversity regarding race, religion, class, and education as presented by Kislingbury (2019).

\section{Exploratory interview}

A probability systematic sampling technique is employed to conduct an exploratory interview and select a sample of 15 undergraduate students who are about to be graduating after few months and will join the market place soon (age range from 19 to 22 years old), they are in their final year of graduation from one of the most reputable private university operating in Egypt (British University in Egypt) with the purpose of verifying the previous findings from literature review and to get clearer understanding of Generation $\mathrm{Z}$ perception of 2020 workplace.

A semi-structured interview was conducted to ask respondents about the following points:

- The important dimensions behind selecting a potential employer to work for over another employer

- The most appealing type of organizations they want to join

- The attractive sector/s and the reasons behind selecting such sector/s

- The most important channel/s used to search for a job or internship

- Whether they check company website or information uploaded on the social media before applying for ajob/internship

- The top channels used to check potential employers' reputation/image before applying for a job/ internship 
After collecting and evaluating responses, it was observed that:

- An attractive financial package is the first and the tempting benefit behind selecting a potential employer for almost $80 \%$ of the respondents.

- They further expressed that work-life balance; learning and career development using digitalized techniques, working in an innovative, pleasant work atmosphere respectively are soft employer value proposition (EVP) drivers in which potential employees seek

This means in 2020, employers that are perceived to offer attractive financial benefits have the best chances to attract the workforce. However, monetary benefits can be easily replicated suggesting that employers who rely on financial benefits only in their employer value proposition (EVP) will not necessarily be at a competitive edge. Soft EVP (e.g. symbolic benefits) drivers are a worthwhile investment in an organization that any employer should focus on along with providing functional benefits.

To attract generation Z; employers should focus on factors like career progression in addition to developing employer brand strategy highlighting a good work-life balance might be more efficient than with other generations because they do value flexible work schedules and remote working as indicated by the majority of respondents.

\section{The most attractive sector/s to generation $Z$}

$41 \%$ of the respondents claimed that they would like to work in telecommunication sector because they like dealing with technology and working on a social platforms, according to their point of view; this sector is considered as a valuable source of innovation potential driven by different mindsets and concepts of thinking, while the other $46 \%$ added that FMCG (fast-moving consumer goods) sector is more appealing to them because it is considered by most of them as a dynamic and competitive sector offering essential products that cannot be substituted one day ( which reflects the need for high job security), providing them with good opportunity for career advancement and only $13 \%$ added that they are passionate about working in the media.

\section{The most appealing type of organization/s}

$66 \%$ of the respondents would rather work for a large multinational corporation as they offer high return, enables the use of innovation and technology in day to day operations, interesting work environment, various opportunities for career progression, while the remaining $34 \%$ respondents claimed that they want to establish their own business as they will apply what has been learned in their university in the market place, as well as being empowered to be involved in decision making and enjoying more flexibility in the work schedule.

\section{Channels used to search for a job or internship}

The most important channels used to search for a job or internship can be summarized into almost $80 \%$ of respondents depend on the use of social media networking sites on searching for internship programs as "they spend most of their time on Facebook and Instagram as claimed by the majority of respondents", along with depending on personal connections/referrals to look for a potential opportunities that will add to their experience, in addition to checking regularly the advertised opportunities posted on the employer's website. 


\section{Potential employers' reputation}

Finally, all respondents emphasized that they definitely check potential employers' reputation via the company website and all the information posted on the website give them indication of a preliminary image of the company inside and if it is not an attractive, innovative and informative website; they won't apply even if they are unemployed.

Asking about the opinion of friends and family on the employer reputation really matters with all the respondents. Those are the main source of information about their future employers and then come at the third category; the reviews on Linkedln or platforms like Glassdoor when making an initial decision based on company rating because it is more credible sources from their own point of view.

\section{The EB Strategy in Practice}

After illustrating on the $\mathrm{Z}$ generation characteristics and considering the importance of building a strong EB strategy, it is important to ask: how can employers develop an appropriate and unique EB strategy in order to appeal for the generation in question and take advantage of the digitalization potential?

Accordingly, the most important elements shaping a strong employer brand can be summarized in the following:

First, organizations should start by the diagnostic phase (internal and external diagnosis), this establishes a framework of the critical analysis of the existing processes inside the organization and practices of other competitors in the market (Arriscado et al., 2019), the employer will receive input directly from the existing employees about how they perceive their current employment experience as they are important ambassadors regarding employer brand (internal diagnosis) (Backhaus, 2016).

During this stage, it's important that the employer should be aware of potential applicants' expectations and the attributes that the organization can offer, which should be appealing to potential employees (external diagnosis), it is also crucial to search about what other competitors are offering to attract and retain employees (what makes other employers unique) (Backhaus, 2016).

\section{Second, employers should assess and shape an authentic, consistent message of what the} organization value

A strong employer brand must deliver to potential employees (Z generation) the value proposition of the brand (Mihalcea, 2017). It is necessary to adapt the package of functional, emotional, and symbolic benefits in its value proposition along with putting into consideration the previously mentioned benefits stated in the exploratory interview required by the generation in question (Arriscado et al., 2019).

For example, the employer should define the employment values in terms of career development with growth opportunities, better work-life balance policies, a pleasant and innovative work environment. This implies that HR strategy must focus on building a growth culture that supports learning and development in the workplace using digitalized techniques that appeals more to target generation; create an environment where flexible work schedules (remote working) are appreciated. It can't be ignored that the top priority of this generation in selecting an employer is offering an attractive financial package. 
Third, after developing the appropriate value proposition it is necessary to communicate the message by leveraging the right channels - For generation Z, it is important to get insights about the employer's culture, working environment, organizational objectives, professional development and growth opportunities, different facilities, using digital media creates an opportunity to establish a strong relationship between employers and employees, fostering a digitalization culture (Arriscado et al., 2019).

Social networks such as LinkedIn, Facebook, youth4work, YouTube, are very efficient, effective, fastest tools in providing insights concerning recruitment process, life-work balance, career development opportunities, organizational culture to the younger generation (Born and Kil Kang, 2015; Balasubramanian et al., 2016). Companies are now utilizing these networking sites to increase brand visibility (Karam and Kitana, 2018).

Employers should employ different strategies to promote life inside the organization through Sharing great content, potential employees want to envision themselves working for a certain organization, an interesting way to do so is by sharing stories, photos and videos about organization's employees across all social media platforms and uploaded on their websites, offices, workspace, recruiting events, interesting projects organizational team works on, awards and recognitions, any additional benefits offered to employees ( for example in-house yoga classes, cafeteria, etc) (Zojceska, 2018).

\section{For example:}

L'Oréal introduced the gamification component in recruitment through the reveal platform and offers site visitors the possibility to discuss with the company employees and to engage in virtual assessment centers (Born and Kil Kang, 2015). While other companies rely on a more contemporary means of electronic recruitment and selection like psychometric tests and work simulation techniques (Balasubramanian et al., 2016).

Companies such as Linkedln, Facebook, Twitter or Google are investing in the development of online talent communities for attracting new employees but also in aggressive marketing campaigns conducted in the academic field or at student job fairs (Born and Kil Kang, 2015).

Companies such as Ford or General Motors have created blogs in order to attract fans of the auto industry or engineers that would like to work for them (Born and Kil Kang, 2015). As per the exploratory interview results Telecommunication and FMCGs could benefit from ford and general motors and apply this practice because these two sectors appear to have a high appeal for Generation Z.

The most important thing to remember when presenting employer brand value on social media is to always be responsive to the target audience, through engaging them by asking questions, responding to comments and likes, personalizing answers, establishing on-time communication (Zojceska, 2018).

Finally, there are many different social media networks that can be used for communicating EB brand values, selecting the right channel is very important and cost-effective, as per the exploratory interview results, the respondents claimed that they spend much time on Facebook and Instagram, there is what organizations need to present (Zojceska, 2018).

Fourth, develop employer branding metrics and measure their effectiveness 
Use data analytics to provide better insight into how effectively EB strategy is being deployed within the organization and the costs involved in the recruitment and selection process as presented by Born and Kil Kang (2015).

Examples of metrics that have been used to measure return on investment (ROI) on employer branding activities as suggested by Moroko and Uncles (2008) and Wallace et al. (2014) were divided into two categories, first external measure that focuses on percentages of accepted job offers, applicants number for each role, cost per hire and time to fill in a certain vacancy and internal measure that focus on absenteeism rate, average tenure length, staff engagement levels, time to productivity, candidate satisfaction rate, total cost of labor to revenue.

\section{Conclusion}

Human Resource Management has entered into a new stage of evolution and war for talent that urges them to reinvent themselves and help in increasing employers attractiveness in the market, this implies establishing an effective digitalized employer branding strategy that addresses the needs and expectations of different generations especially "Z generation" who make up a large share of the global workforce by the year 2020 .

An important challenge for Human Resource practitioners is represented by attracting and retaining Generation $\mathrm{Z}$ members, in order to respond to the needs and expectations of this generation; employer brand value should be developed around offering attractive financial benefit packages, stimulating work offering opportunities for advancement and success, encouraging work-life balance, in addition to creating an innovative and pleasant work environment; accordingly, the main challenge is to develop the right balance of incentives that attract and retain Generation $\mathrm{Z}$ members.

Concerning recruitment, since Generation $Z$ has grown up with the internet, companies should become more agile and technologically reinvent themselves; it has been proved that the internet is the most famous source of information for those who are seeking job opportunities. Generation $\mathrm{Z}$ in specific evaluates organizations through the information posted in the internet before they apply for a job; they want to be sure before they start their professional career with this organizations. The digital age is reshaping the way in which organizations recruit, select and retain the new generation of employees.

Therefore, the implications that have been illustrated above is a starting point that could provide a useful framework for attracting the $\mathrm{Z}$ generation by building an attractive digitalized employer branding strategy. In summary, this is a working paper that provides an initial elaboration on how employers position themselves in the 2020 marketplace during the digitalization era. Since only 15 respondents were included in the exploratory interview so the results are not representing the population and cannot be generalized on Generation Z, which requires further analysis to empirically test potential employees' perception of employer branding among different generations as it is considered as an important topic that requires researchers further attention. 


\section{References}

Al Badawy, T. A.; Fahmy, V. M. and Magdy, M. M. (2017). “Can employer branding raise the retention and motivation of Egyptian employees?", Journal of Competitiveness Studies, 25 (3/4), pp. 250-265.

- Ambler, T. and Barrow, S. (1996). "The employer brand", Journal of Brand Management, 4 (3), 185-206.

App, S.; Merk, J. and Büttgen, M. (2012). “Employer branding: Sustainable HRM as a competitive advantage in the market for high-quality employees", Management revue, 23 (3), 262-278.

- $\quad$ Arriscado, P.; Quesado, H. and Sousa, B. (2019). “Employer branding in the digital era: Attracting and retaining millennials using digital media", In: Communication: Innovation and Quality, pp. 391-403. Springer, Cham.

- Backhaus, K. (2016). “Employer branding revisited", Organization Management Journal, 13 (4), pp. 193-201.

- $\quad$ Backhaus, K. and Tikoo, S. (2004). “Conceptualizing and researching employer branding”, Career Development International, 9, 501-517.

- Bakanauskienė, I.; Lina, Ž. and Justina, V. (2014). “Employer's attractiveness: Employees' expectations vs. reality in Lithuania", Human Resources Management \& Ergonomics, 8, $23-37$.

- Balasubramanian, P.; Vishnu, P. and Sidharth, S. (2016). "Social media as a recruitment tool", International Journal of Industrial Engineering and Management Science, 6 (3), 108-110. Barney, J. (1991). "Firm resources and sustained competitive advantage", Journal of Management, 17 (1), pp. 99-120.

- $\quad$ Born, N. and Kil Kang, S. (2015). "What are best practices in the space of employer branding that enable organizations attract and retain the best talent?. Cornell University, ILR School. Retrieved January 2020 from http://digitalcommons.ilr.cornell.edu/student/86.

- Botha, A.; Bussin, M. and De Swardt, L. (2011). An employer brand predictive model for talent attraction and retention. SA Journal of Human Resource Management, 9 (1), 1-12.

- $\quad$ Crous, S. (2008). Talent makes the rules now. Corporate Research Foundation. retrieved January 2020, from https:/www.bizcommunity.com/Article/196/423/22182.html

- Elving, W. J.; Westhoff, J. J.; Meeusen, K. and Schoonderbeek, J. W. (2013). "The war for talent and quest: The relevance of employer branding in job advertisements for becoming an employer of choice", Journal of Brand Management, 20 (5), pp. 355-373.

- Hieronimus, F.; Schaefer, K. and Schroder, J. (2005). "Using branding to attract talent", McKinsey Quarterly, 3, pp. 12-14.

- Jiang, T. and Iles, P. (2011). "Employer-brand equity, organizational attractiveness and talent management in the Zhejiang private sector; China", Journal of Technology Management in China, 6, 97-110.

- Karam, AA and Kitana, AF (2018). "The impact of social media on human resource management scope activities in Al-Futtaim and Al-Etihad group UAE", International Business Research,11 (12), pp. 145-156.

- Kislingbury, C. (2019). Generation Z - Class 2020, Retrieved January 2020 from: https://www. businesswest.co.uk/members/blog/generation-z-class-2020

- Kuczerska, D. (2018). "Methods of looking for a Job in the modern labor market: Analysis of research on professional drivers", Indian Journal of Computer Science, 3 (1), 31-36

- Lievens, F., Van Hoye, G. and Anseel, F. (2007). Organizational identity and employer image: Towards a unifying framework. British Journal of Management, 18 (1), pp. S45-S59.

- Lievens, F. and Highhouse, S. (2003). "The relation of instrumental and symbolic attributes to a company's attractiveness as an employer", Personnel Psychology, 56 (1), pp. 75-102. 
Lundkvist, H. (2017). A proposal for sustainable employer brand: From market and product theory to sustainable development theories. Economic, Management and Innovation, 9 (2), 5-18

- Macalik, J. and Sulich, A. (2019). "External employer branding of sustainable organizations.", In: International Scientific Conference, Contemporary Issues in Business, Management and Economics Engineering".

- Masdar. (2019). Gen Z Survey. Retrieved January 2020, from https://masdar.ae/en/ strategic-platforms/youth-4-sustainability/gen-z-survey

- Mihalcea, A. (2017). "Employer branding and talent management in the digital age", Management Dynamics in the Knowledge Economy, 5 (2), 289-306.

- Mičík, M. and Mičudová, K. (2018). Employer brand building: Using social media and career websites to attract Generation Y. Economics and Sociology, 11 (3), 171-189.

- Moroko, L. and Uncles, M. D. (2008). "Characteristics of successful employer brands", Journal of Brand Management,16 (3), pp. 160-175.

- Mukherjee, I.; Patra, G. and Dash, C. K. (2018). “Digital employer branding for enabling Gen Y in ITES sector in India", Sumedha Journal of Management, 7 (4), pp. 47-59.

- Munsamy,M. and Venter, A. B. (2009). “Retention factors of management staff in the maintenance phase of their careers in local government", SA Journal of Human Resource Management, 7 (1), pp. 1-9.

- Patel, D. (2017). 11 Environmental causes Gen $Z$ is passionate about. Retrieved January, 2020, from https://www.forbes.com/ sites/deeppatel/2017/10/04/11-environmental-causes-g en-z-is-passionate-about/\#6cbfd8ef1849

- $\quad$ Rodríguez-Sánchez, J. L.; Montero-Navarro, A. and Gallego-Losada, R. (2019). “The opportunity presented by yechnological innovation to attract valuable human resources", Sustainability, 11 (20), pp. 57-85.

- $\quad$ Sharma, R.; Singh, S. P. and Rana, G. (2019). “Employer branding analytics and retention strategies for sustainable growth of organizations", In: Understanding the Role of Business Analytics, pp. 189-205. Springer, Singapore.

- Suikkanen, E. (2010). How does employer branding increase employee retention?. Retrieved January 2020, from https://core.ac.uk/download/pdf/38024728.pdf

- $\quad$ Tabaka, (2019). Gen-Z will make Up 24 percent of the global workforce in 2020: Here's what employers need to know. Retrieved January 2020, from https://www.inc.com/marla-tabaka/ gen-z-will-make-up-24-percent-of-global-workforce-in-2020-heres-what-employers -need-to-know.html

- Wallace, M.; Lings, I.; Cameron, R. and Sheldon, N. (2014). "Attracting and retaining staff: the role of branding and industry image", Workforce Development, Springer, Singapore, pp. 19-36. Published version available from http://doi.org/10.1007/978-981-4560-58-02.

- Worldometer. (2020). "Population in Egypt". Retrieved January 2020, from https://www. worldometers.info/world-population/egypt-population/

- Wright, P. M. and McMahan, G. C. (1992). "Theoretical perspectives for strategic human resource management", Journal of Management, 18 (2), pp. 295-320.

- Xie, Ch.; Bagozzi R. P. and Meland, K. V. (2015). "The impact of reputation and identity congruence on employer brand attractiveness", Marketing Intelligence \& Planning, 33 (2), pp. 124 -146.

- Zojceska, A. (2018). Social Media Recruiting: How to Promote Employer Brand on Social Media. retrieved January (2020), from:https://www.talentlyft.com/en/blog/article/115/socia I-media-recruiting-how-to-promote-employer-brand-on-social-media 